\title{
Relationship between summer monsoon rainfall and cyclogenesis over Bay of Bengal during post-monsoon (October-December) season
}

\author{
Y SADHURAM* (D) and K MANEESHA \\ CSIR-National Institute of Oceanography, 176, Lawsons Bay Colony, Visakhapatnam 530 017, India. \\ *Corresponding author.e-mail: sadhuram@nio.org
}

In this study, an attempt has been made to examine the relationship between summer monsoon rainfall (June-September) and the total number of depressions, cyclones and severe cyclones (TNDC) over Bay of Bengal during the post-monsoon (October-December) season. The seasonal rainfall of the subdivisions (located in south India) (referred as rainfall index - RI), is positively and significantly correlated $(r=0.59$; significant at $>99 \%$ level $)$ with the TNDC during the period, 1984-2013. By using the first differences (current season minus previous season), the correlations are enhanced and a remarkably high correlation of 0.87 is observed between TNDC and RI for the recent period, 1993-2013. The average seasonal genesis potential parameter (GPP) showed a very high correlation of 0.84 with the TNDC. A very high correlation of 0.83 is observed between GPP and RI for the period, 1993-2013. The relative vorticity and mid-tropospheric relative humidity are found to be the dominant terms in GPP. The GPP was 3.5 times higher in above (below) normal RI in which TNDC was 4 (2). It is inferred that RI is playing a key role in TNDC by modulating the environmental conditions (low level vorticity and relative humidity) over Bay of Bengal during post-monsoon season which could be seen from the very high correlation of 0.87 (which explains $76 \%$ variability in TNDC). For the first time, we show that RI is a precursor for the TNDC over Bay of Bengal during post-monsoon season. Strong westerlies after the SW monsoon season transport moisture over the subdivisions towards Bay of Bengal due to cyclonic circulation. This circulation favours upward motion and hence transport moisture vertically to mid-troposphere which causes convective instability and this in turn favour more number of TNDC, under above-normal RI year.

\section{Introduction}

Forecasting of seasonal cyclone activity around Australia (Nicholls 1984, 1992) and southern Pacific region (Revell and Goulter 1986) were reported earlier. Balachandran and Geetha (2012) developed a statistical method to predict the cyclone days over north Indian Ocean. Singh (2008) studied the relationship between Indian Ocean Dipole Mode Index (IODMI) and the frequency of cyclones over Bay of Bengal. He found that IODMI during September-October is negatively correlated $(r=-0.4$; significant at $99 \%$ level) with the frequency of cyclones during November. Recently, Sadhuram (2016) showed that the sea surface temperatures (SSTs) in the northern Australia-Indonesia region $\left(05^{\circ}-15^{\circ} \mathrm{S} ; 120^{\circ}-160^{\circ} \mathrm{E}\right)$ are useful to predict TNDC during post-monsoon (OctoberDecember) season. The influence of ENSO (El-Nino Southern Oscillation) and IOD (Indian Ocean Dipole) on the cyclogenesis over Bay of Bengal were reported earlier (Girish Kumar and Ravichandran 2012; Felton et al. 2013). The role of MJO (MaddenJulian Oscillation) (Kikuchi and Wang 2010) and

Keywords. Cyclones; Bay of Bengal; summer monsoon; rainfall; genesis potential parameter; post-monsoon. 


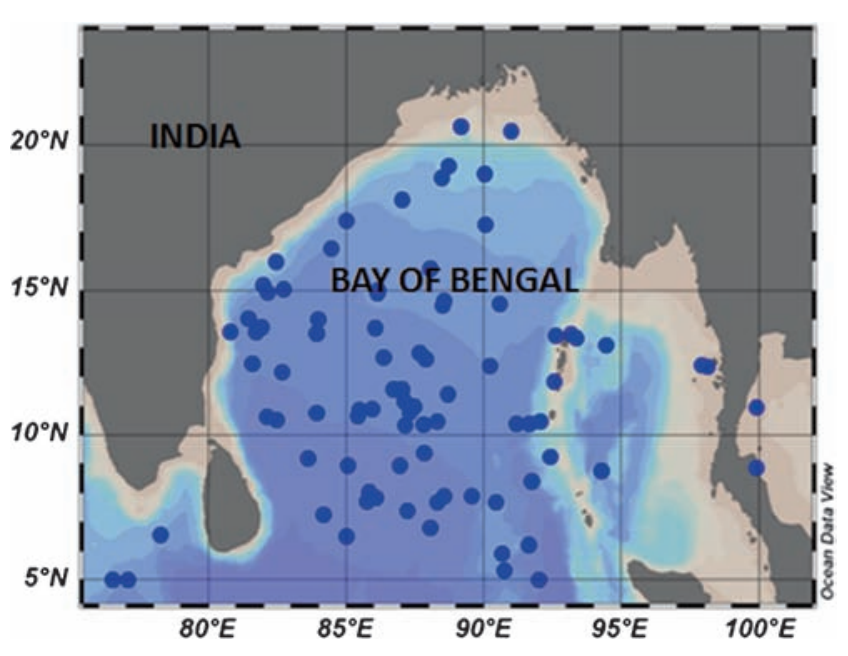

Figure 1. Genesis locations of the depressions, cyclones and severe cyclones over Bay of Bengal during post-monsoon (October-December) season for the period, 1984-2013.

El-Nino Modoki (Sumesh and Ramesh Kumar 2013) in the cyclogenesis over north Indian Ocean were reported earlier. Li et al. (2015) studied the inter-annual variability of cyclones over Bay of Bengal during peak monsoon (October-November) season and concluded that the frequency of cyclones is modulated by negative and positive IOD rather than El-Nino and La-Nina. In this study, the relationship between southwest monsoon rainfall (June-September) and TNDC during post-monsoon (October-December) season (genesis locations are shown in figure 1) has been examined using the data for the period, 1984-2013.

\section{Data and methodology}

Time series rainfall data for all India, major regions (northwest, central-northeast, northeast, west-central and peninsular) and subdivisions (shown in figure 2) are downloaded from IITM (Indian Institute of Tropical Meteorology) website, www.tropmet.res.in, for the period, 1984-2013. Data is not considered for the sub-division numbers $(1,2,12,13,15,36)$ located over hilly and island regions. The data on TNDC during OctoberDecember was obtained from IMD (India Meteorological Department) website, www.imd.gov.in. TNDC was 96 during 1984-2013. There were 42 depressions, 20 cyclones and 34 severe cyclones. TNDC was maximum (6) in 1985 and the minimum (1) was observed in 1986, 1997, 2004, 2006 and 2009. To remove the trends and non-stationarity in the time series, the first differences are normally used to compute the correlations (Nicholls 1984). Following this methodology, the correlations with the first differences (current season minus previous season) in rainfall and TNDC are used in the computations for the period, 1984-2013.

\subsection{Cyclone genesis parameter}

Gray (1975) defined cyclone genesis parameter as the product of six parameters, viz., SST above $26^{\circ} \mathrm{C}$ up to a depth of $60 \mathrm{~m}$, mid-troposphere relative humidity, vertical gradient of equivalent potential temperature, coriolis parameter, inverse of vertical wind shear and relative vorticity in the lower troposphere. Several studies (Mc Bride and Zehr 1981; Royer et al. 1998; De Maria et al. 2001; Emanuel and Noolan 2004; Camargo et al. 2007) used different parameters to estimate the cyclone genesis parameter over different oceanic regions. The roles of intra-seasonal oscillation and MJO (Madden-Julian oscillation) in the genesis of cyclones over north Indian Ocean was elaborately discussed by Kikuchi and Wang (2010). Genesis potential index (GPI) developed by Emanuel and Noolan (2004) was modified by Murakami et al. (2011) introducing vertical velocity, in addition to the four parameters (absolute vorticity, relative humidity, wind shear, maximum potential intensity). The modified index was computed for the Indian Ocean to examine the cyclone genesis with reference to MJO activity (Tsuboi and Takemi 2014). Roy Bhowmik (2003) developed a genesis index for Bay of Bengal using relative vorticity and convergence at $850 \mathrm{hPa}$ and shear coefficient ([25-vertical wind shear between 200 and $850 \mathrm{hPa}] / 20)$. Kotal et al. (2009) proposed a genesis potential parameter (GPP) using relative vorticity at $850 \mathrm{hPa}$, wind shear between 200 and $850 \mathrm{hPa}$, average relative humidity at 700 and $500 \mathrm{hPa}$ and thermal instability (temperature difference between 850 and $500 \mathrm{hPa}$ ). They have used data for 35 tropical disturbances during 1995-2005, for Bay of Bengal. Except seven cases, all were during the post-monsoon season. This index is followed by IMD to identify the potential genesis locations for cyclones few days in advance over the north Indian Ocean. Hence, we have computed the GPP using the following equation,

$$
\begin{aligned}
\mathrm{GPP} & =\frac{\xi_{850} \times M \times I}{S} & & \text { if } \xi_{850}>0, M>0 \text { and } I>0 \\
& =0 & & \text { if } \xi_{850} \leq 0, M \leq 0 \text { or } I \leq 0
\end{aligned}
$$

where $\xi_{850}=$ low-level relative vorticity (at $850 \mathrm{hPa}$ ) in $10^{-5} \mathrm{~S}^{-1}, \mathrm{~S}=$ vertical wind shear between 200 and $850 \mathrm{hPa}\left(\mathrm{m} \mathrm{s}^{-1}\right) ; M=\frac{[R H-40]}{30}=$ middle troposphere relative humidity, where $R H$ is the average relative humidity between 700 and $500 \mathrm{hPa}$. $I=\left(\mathrm{T}_{850}-\mathrm{T}_{500}\right)^{\circ} \mathrm{C}=$ middle tropospheric instability (temperature difference between 850 and $500 \mathrm{hPa}$ ).

National Center for Environmental Prediction (NCEP)-National Center for Atmospheric Research 
$(\mathrm{NCAR})$ monthly datasets at $2.5^{\circ} \times 2.5^{\circ}$ (Kalnay et al. 1996) are used to compute the average GPP (area: $5^{\circ}-20^{\circ} \mathrm{N} ; 80^{\circ}-100^{\circ} \mathrm{E}$ ) during the postmonsoon season over Bay of Bengal. Since the genesis locations during the period are confined to $5^{\circ}-20^{\circ} \mathrm{N} ; 80^{\circ}-100^{\circ} \mathrm{E}$ (figure 1 ), average monthly values in this box are used to compute GPP.

\section{Results and discussion}

The correlations of TNDC with the all India rainfall and major regions (northwest, central-northeast, northeast, west-central, peninsular) (shown in figure 2) during summer monsoon season are computed for the period, 1984-2013. The correlations are weak with the all India and major regions rainfall except with the west-central region which showed a correlation of 0.33 (significant at $<95 \%$ level) (not shown). Then the computations are repeated with the rainfall over different subdivisions and the results are shown in figure 3. Subdivisions of hill regions and islands $(1,2,12,15,16$, 36 ) are excluded from the analysis. Significance levels $(95 \%$ and $99 \%)$ are indicated. Sub-division rainfall over 4, 6, 7 and 8 showed negative correlations with the TNDC. Rainfall over 11, 13, 23, 26, 28 and 31 showed positive and significant (>95\% level) correlations with the TNDC. Highest correlations of 0.52 and 0.59 are observed (figure 3 ) with the rainfall of the sub-divisions Marathwada (25) and Telangana (29) (figure 2) respectively which are located in south India. The average rainfall of 25 and 29 yielded a correlation of 0.59 which is significant at $>99 \%$ level for the period, 1984-2013. The inter-annual variability of the TNDC, average summer monsoon rainfall (JJAS) of sub-divisions Marathwada and Telangana (hereafter it will be referred as 'rainfall index' - RI) and GPP (this has to be multiplied by $10^{-6}$ to get the actual values, hereafter integer part will be referred) for the period, 1984-2013 are shown in figure 4. The TNDC was 96 during the above period. Maximum number (6) was observed in 1985 and the minimum number (1) was observed in the years, 1986, 1997, 2004, 2006 and 2009. RI varied from 47 to $122 \mathrm{~cm}$. The maximum RI of $122 \mathrm{~cm}$ was observed in 1988 in which TNDC was 5 . The minimum RI of $47 \mathrm{~cm}$ was observed in 1984 while the TNDC was 3. The correlation between RI and TNDC for the 30-year period (1984-2013) with the actual values is found to be 0.47 (significant at $>99 \%$ level) (figure $4 \mathrm{a}$ ).

Homogeneous Monsoon Regions

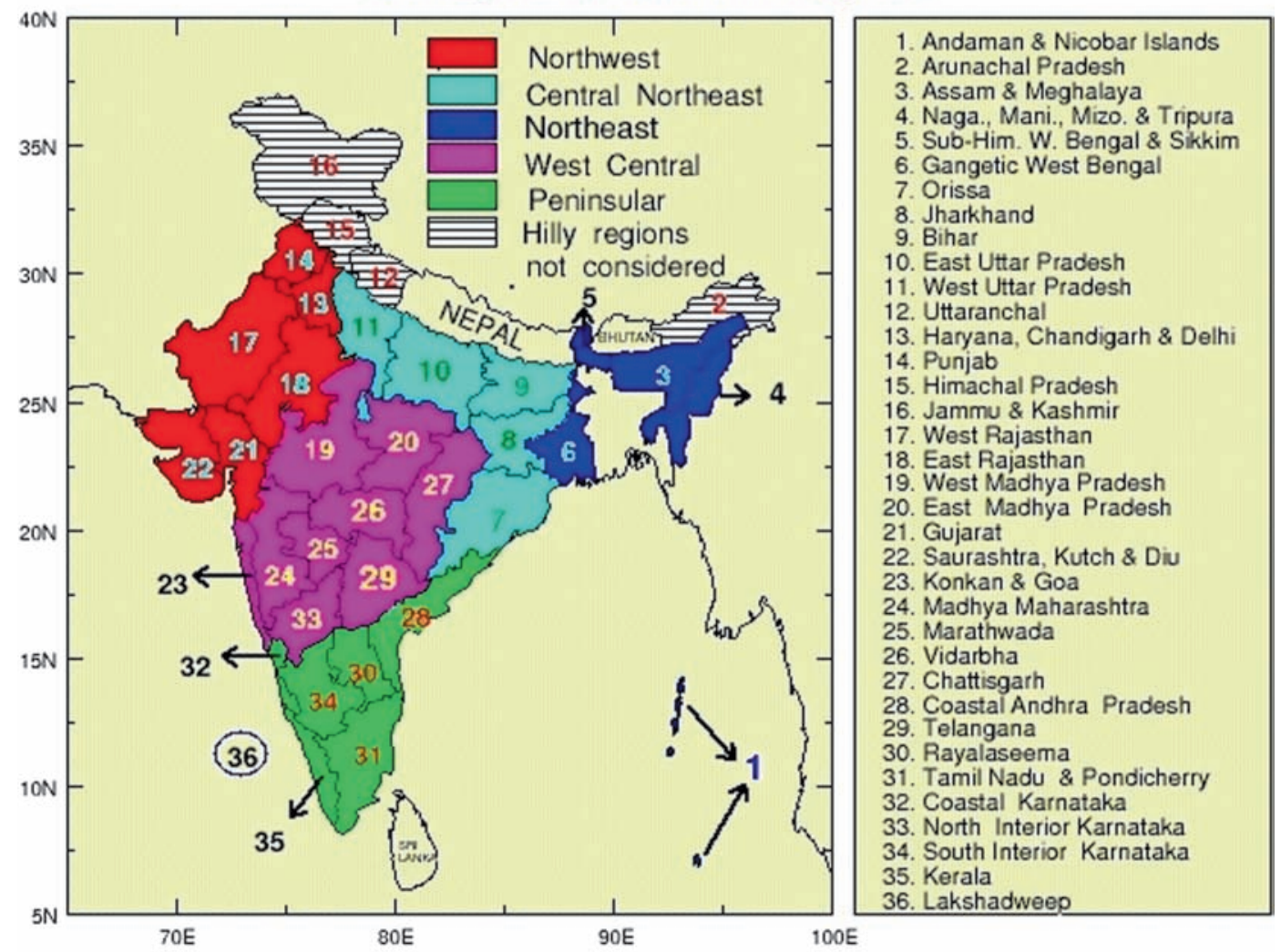

2005, Indan Institute of Tropical Meteorobogy

Figure 2. Homogeneous monsoon regions and sub-divisions (source: www.tropmet.res.in). 
The GPP varied from 0 to 7.67. The maximum value of 7.67 was observed in 2005 in which TNDC was 5. GPP was 0 in 1994, 1997, 2004, 2006 and 2012. The vorticity was negative in the above

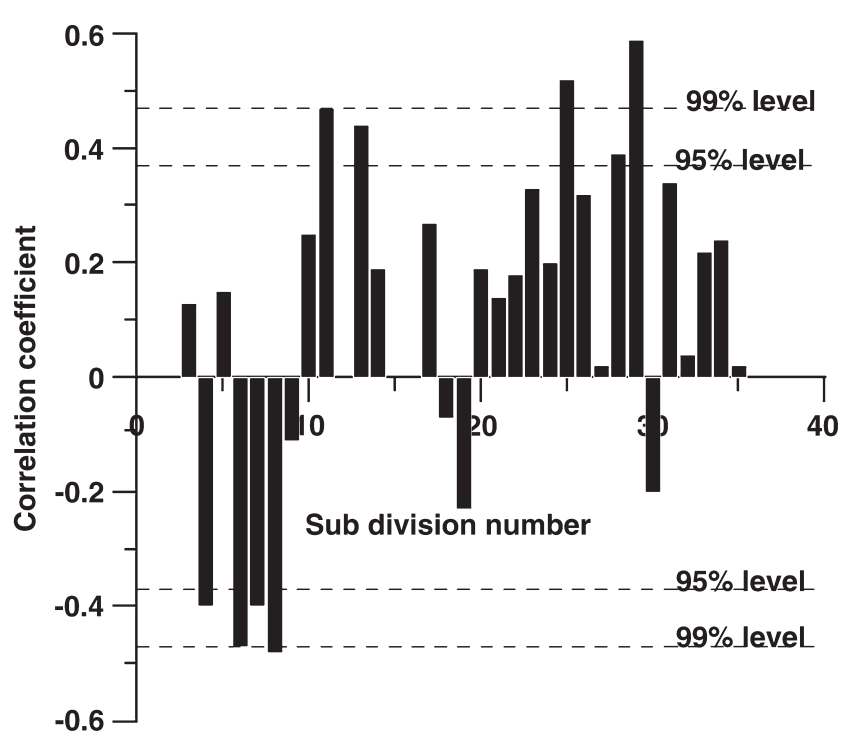

Figure 3. Correlations of TNDC with the sub-divisional rainfall during summer monsoon (June-September) season for the period, 1984-2013. 95\% and 99\% significant levels are indicated as dotted lines. years except in 2004 in which the second term $[(R H-40) / 30]$ was negative. Hence, as per equation (1), GPP is considered as 0. TNDC varied from 1 to 3 in the above years. The correlation between GPP and TNDC (actual values) is found to be 0.57 (significant at $>99 \%$ level) (figure $4 \mathrm{~b}$ ). The variability of GPP and RI is shown in figure 4(c). It is interesting to see a close association between GPP and RI and the correlation is 0.41 (significant at $>95 \%$ level). Nicholls (1984) showed that the first differences of the parameters would give better correlations than with the actual values. The computations have been repeated with the first differences for the period, 1993-2013 and the scatter plots are shown in figure 5. A remarkably high correlation of 0.87 (significant at $>99 \%$ level) is observed between RI (differences) and TNDC (differences) (figure 5a). Very high and positive correlation of 0.84 is observed between TNDC (differences) and GPP (differences) (figure 5b). GPP (differences) is found to be strongly correlated with the RI (differences $)(r=0.83$; significant at $>99 \%$ level $)$ (figure 5c). To compare the correlations with the actual values and with the differences, the results for the two periods, viz., 1984-2013 and 1993-2013 are shown in table 1 . One can see a substantial improvement in the correlations by using the first differences under both the periods. Except one

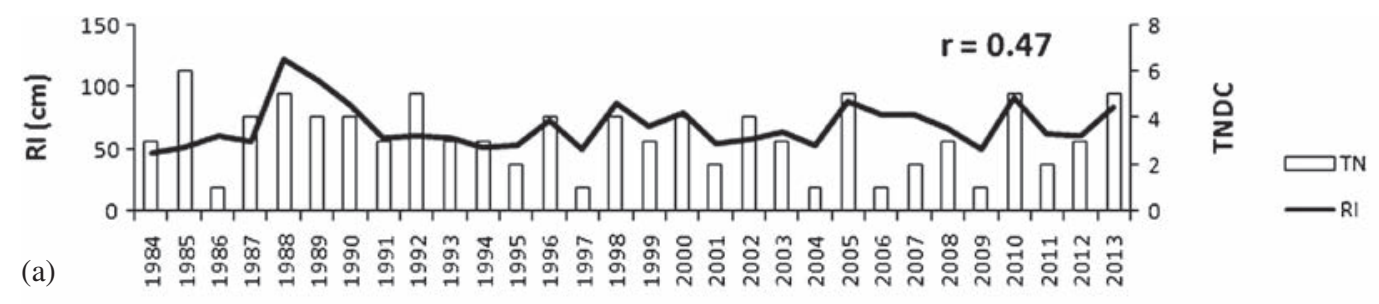

Year

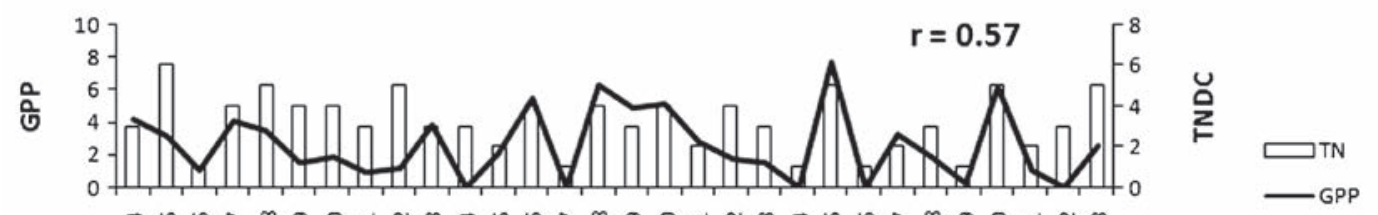

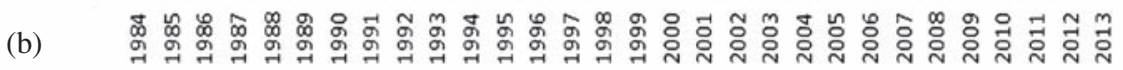

Year

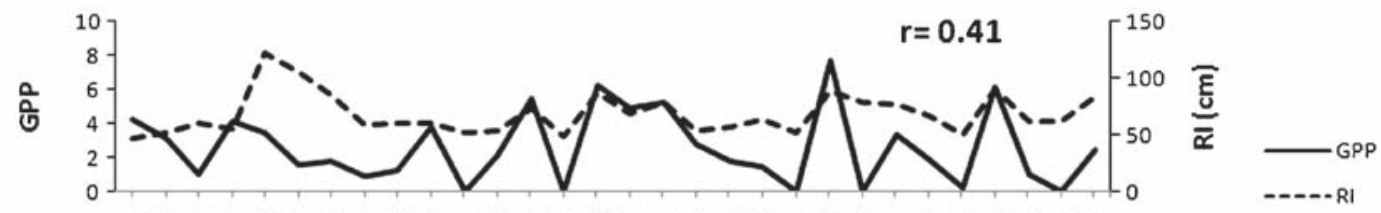

(c)

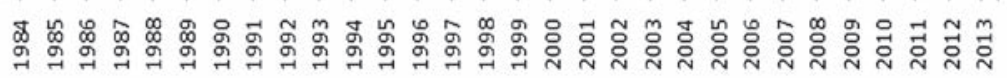

Year

Figure 4. Inter-annual variability of (a) RI (cm) and TNDC, (b) GPP and TNDC and (c) RI and GPP for the period, 1984-2013. Correlations shown here are computed with the actual values (GPP has to be multiplied with $10^{-6}$ to get actual values). 

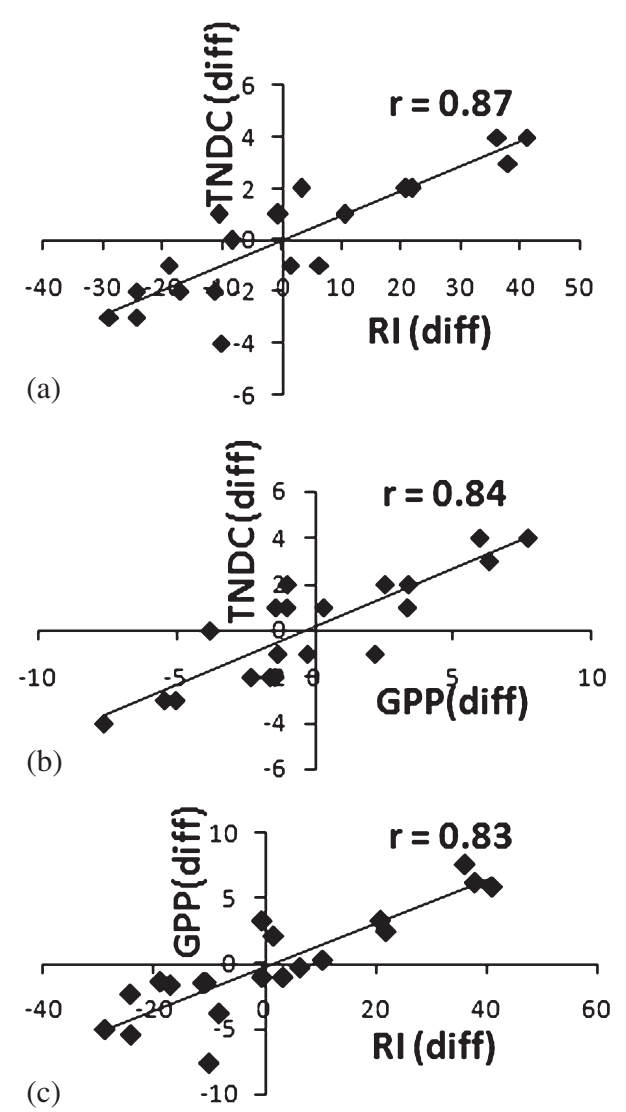

Figure 5. Scatter plots of (a) RI (differences) vs. TNDC (differences), (b) GPP (differences) vs. TNDC (differences) and (c) RI (differences) vs. GPP (differences), for the period 1993-2013 (GPP (diff) has to be multiplied with $10^{-6}$ to get actual values).

value $(r=0.38)$, all the other correlations are significant at $>99 \%$ level. To examine the variability of different terms in equation (1) and GPP with reference to RI, below normal (I) (RI $<67 \mathrm{~cm}$; average of 1993, 1994, 1995, 1997, 2001, 2002, 2003, 2004, 2008, 2009, 2011, 2012) and above normal (II) (RI $>67 \mathrm{~cm}$; average of 1996, 1998, 1999, 2000, 2005, 2006, 2007, 2010, 2013) composites are prepared and the results are shown in table 2 . It is interesting to see that the relative vorticity is more than 3 times higher in above normal (II) in which the TNDC was 4.0. Relative humidity was about $8 \%$ higher in above normal (II) while the wind shear and instability are almost the same. GPP was about 3.65 times higher under above normal (II) compared with that under below normal (I) case. $R H$ is slightly higher under above normal case which favours cyclogenesis. To examine the link between RI and different terms in equation (1), the correlations (with first differences) are computed for the period, 1993-2013. RI is positively and significantly correlated $(r=0.79$ and 0.69$)$ with the vorticity and relative humidity. The correlation with the wind shear is weak while a negative correlation $(r=-0.57)$ is found with the instability.
Table 1. Correlations with actual and first differen ces for the periods, 1984-2013 and 1 993-2013.

\begin{tabular}{lcc}
\hline & $1984-2013$ & $1993-2013$ \\
\hline RI vs. TNDC & 0.47 & 0.69 \\
1 & 0.59 & 0.87 \\
2 & & \\
TNDC vs. GPP & 0.56 & 0.72 \\
1 & 0.72 & 0.84 \\
2 & & \\
GPP vs. RI & 0.38 & 0.72 \\
1 & 0.57 & 0.83 \\
2 & & \\
\hline (1 with actual data; 2: with first differences; all \\
correlations with first differences (2) are signifi- \\
cant at >99\% level).
\end{tabular}

Table 2. Variability of the different parameters under below (I) and above (II) normal composites.

\begin{tabular}{lcc}
\hline Parameter & I & II \\
\hline Relative vorticity $\left(\mathrm{sec}^{-1}\right)$ & $0.076 \times 10^{-5}$ & $0.24 \times 10^{-5}$ \\
Relative humidity (\%) & 48 & 52 \\
Wind shear $\left(\mathrm{m} \mathrm{s}^{-1}\right)$ & 4.44 & 4.36 \\
Instability $\left({ }^{\circ} \mathrm{C}\right)$ & 21.64 & 21.44 \\
GPP & 01.26 & 04.60 \\
TNDC & $2.3(2.0)$ & $3.7(4.0)$ \\
\hline
\end{tabular}

Average of $\mathrm{RI}=67.0 \mathrm{~cm}$ and $\mathrm{TNDC}=3.0$ for the period, 1993-2013.

From this analysis, it may be mentioned here that low level vorticity and relative humidity are influenced by RI. Hence, it is inferred that the RI during summer monsoon is playing a key role in TNDC by modulating the environmental conditions (vorticiy, relative humidity) over Bay of Bengal during post-monsoon season. Since GPP and TNDC have a very high correlation of 0.84 , it appears that RI is influencing TNDC through GPP, which could be seen clearly from the results shown in tables 2 and 3 .

Kumar and Krishnan (2005) have reported the negative relation between ISMR and tropical cyclone activity over north Pacific region. The enhanced cyclogenesis during weak monsoon years is found to be associated with enrichment of low-level cyclonic vorticity anomalies over a wide region of subtropical Pacific extending from the China Sea, Taiwan and the Philippines region to the central Pacific. They have attributed the observed relation to the inter-annual variability of large-scale IndoPacific circulation with response to ENSO. The present study reported the observed relationship between ISMR and TNDC during post-monsoon. The relationship between RI and TNDC, two contrasting years, viz., $2005(\mathrm{RI}=88.5 \mathrm{~cm}$; above 
Table 3. Correlations of $R I$ with the GPP, TNDC and different terms in equation (1) during the period, 1993-2013. First differences are used in the computations.

\begin{tabular}{lc}
\hline Parameter & RI \\
\hline TNDC & 0.87 \\
GPP & 0.83 \\
Vorticity & 0.79 \\
Relative humidity & 0.69 \\
Wind shear & 0.34 \\
Instability & -0.57 \\
\hline
\end{tabular}

All the correlations are significant at $>99 \%$ level except one value (0.34).

normal; TNDC $=5$; negative IOD) and $2009(\mathrm{RI}=$ $49.8 \mathrm{~cm}$; below normal; TNDC $=1$; positive IOD) are selected. The wind vectors at $850 \mathrm{hPa}$ and relative humidity at $600 \mathrm{hPa}$ are examined over Bay of Bengal from October to December in the above years. A dominant cyclonic circulation was observed over central Bay of Bengal from October to December in 2005 which was absent in 2009. $R H$ at $600 \mathrm{hPa}$ was also high in this region in $2005 \mathrm{com}-$ pared with that in 2009 (not shown). The average relative vorticity over Bay of Bengal during postmonsoon 2005 was $4.0 \times 10^{-6} \mathrm{sec}^{-1}$ while it was only $1.7 \times 10^{-7} \mathrm{sec}^{-1}$ in 2009 , one order less than the above. The average $R H$ at $600 \mathrm{hPa}$ was $53 \%$ and $45 \%$ in 2005 and 2009, respectively. Strong westerlies after the SW monsoon season transport moisture over the sub-divisions (Marathwada and Telangana, figure 2) towards Bay of Bengal due to the cyclonic circulation. This circulation favours upward motion and hence transport moisture vertically to mid-troposphere which causes convective instability and this in turn favour more number of TNDC, under above normal RI year. Hence, TNDC was 5 in 2005 and only 1 in 2009. IOD phenomenon modulates the meridional circulation by inducing anomalous convergence (divergence) patterns over the Bay of Bengal during positive (negative) IOD events, leading to excessive (deficit) monsoon rainfall over the monsoon trough region (Ashok and Guan 2004). When the ENSO co-occurred with the positive phase of the IOD, the ENSO-induced anomalous subsidence is neutralized/reduced by the anomalous IOD-induced convergence over the Bay of Bengal. Li et al. (2015) also reported more number of tropical cyclones over Bay of Bengal during October-November in negative IOD than in positive IOD which supports the above view. From this, it may be inferred that low level vorticity and $R H$ play a dominant role in TNDC during postmonsoon season over Bay of Bengal by influencing the GPP which has a very high correlation with the RI (figure 5).

\section{Conclusions}

In this study, the relationship between summer monsoon rainfall and TNDC during post-monsoon season has been examined using the data for the period, 1984-2013. RI is extremely well correlated with the GPP and TNDC for the recent period, 1993-2013. GPP is more than 3.5 times higher under above normal RI compared with that below normal which is responsible for high (low) TNDC observed. Strong westerlies after the SW monsoon season transport moisture over the sub-divisions towards Bay of Bengal due to the cyclonic circulation. This circulation favours upward motion and hence transport moisture vertically to midtroposphere which causes convective instability and this in turn favour more number of TNDC, under above normal RI year. It appears that the $\mathrm{RI}$ is modulating the environmental conditions (low level vorticity, relative humidity) over Bay of Bengal which in turn influence the TNDC during post-monsoon season. RI appears to be a precursor for the TNDC over Bay of Bengal during post-monsoon season.

\section{Acknowledgements}

The authors would like to thank Dr S W A Naqvi, Director, CSIR-NIO, Goa and Dr V S N Murty, Scientist-in-Charge, CSIR-NIO Regional Centre, Visakhapatnam, for the support and encouragement. Senior author, Y Sadhuram would like to thank CSIR, New Delhi, for providing the Emeritus Scientist scheme. Thanks to the project teams of NOAA, IITM and IMD for making the datasets available on their websites. The authors would like to thank both the reviewers for their valuable suggestions which helped to improve the original version of the manuscript. NIO contribution number 5918.

\section{References}

Ashok K and Guan Z 2004 Individual and combined influences of ENSO and the Indian Ocean Dipole on the Indian summer monsoon; J. Climate 17 3141-3155.

Balachandran S and Geetha B 2012 Statistical prediction of seasonal cyclone activity over north Indian Ocean; Mausam 63 17-28.

Camargo S J, Emanuel K A and Sabel A H 2007 Use of a genesis potential index to diagnose ENSO effects on tropical cyclone genesis; J. Climate 20 4819-4834.

De Maria M, Knaff J A and Bernadette H C 2001 A tropical cyclone genesis parameter for the tropical Atlantic; Wea. Forecasting 16 219-233.

Emanuel K A and Noolan D S 2004 Tropical cyclone activity over global climate; Proc. 26th Conference on Hurricane and Tropical Meteorology; FL, Miami. 
Felton C S, Subrahmanyam B and Murty V S N 2013 ENSO-modulated cyclogenesis over the Bay of Bengal; J. Climate 26 9806-9818.

Girishkumar M S and Ravichandran M 2012 The influences of ENSO on tropical cyclone activity in the Bay of Bengal during October-December; Geophys. Res. Lett. 117 C02033, doi: 10.1029/2011JC007417.

Gray W M 1975 Tropical cyclone genesis: Dept. Atmos. Sci., paper 232, Colorado State University, Port Collins, Co, USA, 121p.

Kalnay et al. 1996 NCEP/NCAR 40 year reanalysis project; Bull. Am. Metor. Soc. 77 437-470.

Kikuchi K and Wang B 2010 Formation of tropical cyclones in the northern Indian Ocean associated with two types of tropical intra seasonal oscillation modes; J. Meteor. Soc. Japan 88 475-496.

Kotal S D, Kundu P K and Roy Bhowmik S K 2009 Analysis of cyclogenesis parameter for developing and nondeveloping low pressure systems over the India sea; Nat. Hazards 50 389-402.

Kumar V and Krishnan R 2005 On the association between the Indian summer monsoon and the tropical cyclone activity over northwest Pacific; Curr. Sci. 88 602612.

Li Z, Li T, Yu W, Li K and Liu Y 2015 What controls the inter annual variation of tropical cyclone frequency over Bay of Bengal in the peak post-monsoon season?; Atmos. Sci. Lett., doi: 10.1002/asl.636.

Mc Bride J L and Zehr R M 1981 Observational analysis of tropical cyclone formation. Part II: Comparison of nondeveloping versus developing systems; J. Atmos. Sci. 38 1132-1151.
Murakami H, Wang B and Kitoh A 2011 Future change of western north Pacific typhoons: Projections by a 20-km mesh global atmospheric model; J. Climate 20 4819-4834.

Nicholls N 1984 The southern oscillation, sea surface temperature and inter annual fluctuations in Australian seasonal cyclone activity; J. Climatol. 4 661-670.

Nicholls N 1992 Recent performance of a method for forecasting Australian seasonal tropical cyclone activity; Aust. Met. Mag. 40 105-110.

Revell C G and Goulter S W 1986 Lagged relationships between the southern oscillation and numbers of tropical cyclones in the southern pacific region; Mon. Wea. Rev. $1142669-2670$.

Roy Bhowmik 2003 An evalution of cyclone genesis parameter over the Bay of Bengal using model analysis; Mausam $54355-358$.

Royer J F, Chauvin F, Timbal B, Araspin P and Grimal D 1998 A GCM study of the impact of greenhouse gas increase in the frequency of occurrence of tropical cyclones; Clim. Change 38 307-343.

Sadhuram Y 2016 Can we predict the frequency of cyclones over Bay of Bengal during October-December?; Mausam (in press).

Singh O P 2008 Indian ocean dipole mode and tropical cyclone frequency; Curr. Sci. 94 29-31.

Sumesh K and Ramesh Kumar M R 2013 Tropical cyclones over north Indian Ocean during El Nino Modoki years; Nat. Hazards 68 1057-1074.

Tsuboi A and Takemi T 2014 The inter-annual relationship between MJO activity and tropical cyclone genesis in the Indian Ocean; Geosci. Lett. 19, doi: 10.1186/2196-4092-1-9. 